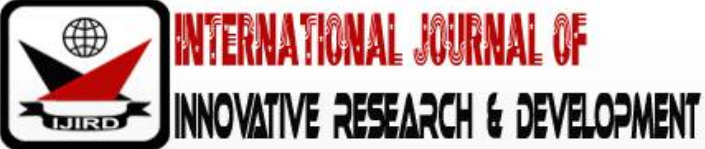

ISSN 2278 - 0211 (Online)

\section{The Impact of Internal Business Processes on Competitiveness of Hotel Accommodation Business in Rwanda}

\begin{tabular}{c}
\hline Gabriel Opare-Obuobisa \\
MBA Student, School of Business, \\
Jomo Kenyatta University of Agriculture and Technology, Kenya \\
Dr. Mulyungi J. Patrick \\
Lecturer, School of Business studies \\
Jomo Kenyatta University of Agriculture and Technology, Kenya
\end{tabular}

\begin{abstract}
:
The purpose of this study was to investigate the impact of internal business process on the competitiveness of hotel accommodation segment in Rwanda. The target population was 120 with a sample size of 92 workers of Serena Hotel in Kigali. The respondents were stratified into two classes to be specific officials accountable for execution contracting and heads of offices to be specific; ICT, Human Resource Management, Finance, and Customer administration.

A poll was utilized as primary instrument for information accumulation. The study utilized both essential and optional information, where surveys were utilized for information gathering. Information gathered was processed through Statistical package for Social Sciences (SPSS). Out of the 92 overviews offered out to the examined respondents, 72 examinations were done and returned. This response rate of $78.2 \%$ was viewed as high for appraisal. As shown by Baruch and Holtom (2008), 52.7\% is the average level of response rate from a survey of several social science studies satisfactory for evaluation and hypothesis of the outcomes.

The study recommends that for an organization to have a significant impact in its industry and gain competitive edge over its competitors, it will have to be aggressive with its internal business processes. The hotel accommodation business mainly thrives on these alongside other variables for success and the capacity to reinforce these strategies with put the organization ahead. This is also practical as many clients are retained through positive experiences with all departments in the hotel.

Majority (84.6\%) of the respondents indicated that their organization strives to improve quality as part of its internal business mechanisms to gain competitive advantage. Again, majority (90. 5\%) of respondents indicated that the organizations certifications are trusted worldwide and as a result many customers are confident doing lodging with the hotel. Further, majority (84.3\%) or respondents indicated that the organization provided quality service to its customers as part of its internal business drive to maintain its clients and gain a competitive advantage. While a lower proportion expressed confidence in the organization's tendering process, overall, the respondents rated the organization's internal business perspective very highly.
\end{abstract}

Keywords: Internal business process, competitiveness, capacity

\section{Background}

If a hotel business wants to gain competitive advantage, it's imperative for it to consider the determined sequential steps to be taken for generating results considering the competitive lodging segments in the hotel business here in Rwanda. The core objective of internal business process is to serve customers in a better way as with each passing day markets are becoming more competitive with new players entering. The internal business processes comprise of factors which directly impact the success and approach of operations. Managing the strengths of internal operations is the key to authoritative aggressiveness in the Hotel accommodation business in Rwanda.

Internal business processes create and deliver the value proposition for customers. The objectives therefore in the strategy map's internal processes perspectives must describe how the organization intends to maintain and control authoritative aggressiveness.

Firstly, several industries with a global dimension have embarked on serious capacity management approaches. Hotel accommodation businesses have been more concerned with enhancing capacity management with an aim of regulating demand and supply of their services (Pullman and Rodgers, 2009). Capacity utilization has been referred to as "demand management" (Crandall and Markland, 1996) or "managing capacity and demand (Fitzsimons and Fitzsimmons, 2004)

Secondly, Order response time. This is the period between when a customer makes a request and a response is given. In a small business, response time plays a significant role in retaining customers. Response time is important in the 
delivery of service since it affects customer satisfaction and behavioral intentions (Klassen and Rohleder, 2002). Service speed could affect customer experiences, where delays contribute to unfavorable experiences. Since the hotel accommodation segment in Rwanda is a growing one, it is important to consider its role in competitive advantage for the organization.

Thirdly, process capability is crucial for the organization's competitiveness. Research exploring the ways of improving service innovation capability is scant. In addition, while social capital cultivates the power of innovation, research on the process of transforming available resources embedded in social interaction into actual service innovation capability is limited as well (Tang, Wang and Tang, 2015). Hotel accommodation businesses will have to commit resources like technology in vast capacities to ease up processes in this area.

\section{Literature Review}

Dynamic limit framework considers the limit of a firm to consolidate, structure, and reconfigure inside and outside abilities to address rapidly developing situations. This system or hypothesis alludes to the assets in the asset base hypothesis as proposed by Barney, Wright and Ketchen (2001). They are those specific physical (explicit equipment, geographic zone) human (capacity in science) and definitive (pervasive arrangements control) assets that can be used to execute worth-making methods. On the other hand, watching dynamic breaking points are the pioneer dynamic and key schedules by which administrators change their bit of leeway base, acquire and shed assets, organize them together and recombine them to convey new respect making frameworks. Teece (2009) depicts dynamic point of confinement as the association's capacity to encourage, structure, and reconfigure inside and outside aptitudes to address quickly propelling conditions. Affiliations and their delegates need the ability to adjust quickly and to gather essential assets. New crucial assets, for instance, limit, advancement, and customer info must be fused inside the association. Existing distinct advantages must be changed or reconfigured. Dynamic capacity is fundamentally the learning of an affiliation, progression of new assets and the difference in existing assets. Teece, (2009) after some time an organization's favorable circumstances may advance toward getting to be co-explicit, inferring that they are especially significant in blend. A model is the spot the physical assets (for instance the plants), HR (for instance the researchers) and the authorized advancement (for instance licenses and verifiable data) of an association give a synergistic blend of relating assets. Organizing, the process of structuring human and physical resources in order to accomplish organizational objectives, involves dividing tasks into jobs, specifying the appropriate department for each job, determining the optimum number of jobs in each department, and delegating authority within and among departments (Burton, Obel, Håkonsson, 2015).

According to Pullman and Rodgers (2009), capacity or utilization refers to the ability of a given industry to balance demand from clients as well as the potential of the service providers to offer quality services. On this background, the study seeks to address the question of whether the role of capacity management in the hotel accommodation business is to match supply with demand or to match demand with supply. It also explores the extent to which each case is true. The fluctuating economic performance in the developed countries and particularly in Asia has had significant impact on the number of tourists visiting Rwanda. With demand capacity utilization, there is an attempt to influence when and how visitors visit the hotel facility (Pullman and Rodgers, 2010) whereas the other twist of capacity utilization ensures that sufficient capacity exist to meet this existing demand (Klassen and Rohleder, 2002). Capacity decisions is therefore one of the most significant strategic operational concerns that affects how well the business will respond to market today and in the future (Saarinen, Rogerson \& Hall 2017; Efendioğlu and Bulkan, 2017).

Regarding response time, it is important for hotel accommodation businesses to consider speed of delivery since it affects customer satisfaction and behavioral intentions (Jones, 2008). Service speed could affect customer experiences, where delays contribute to unfavorable experiences. Jones (2008) emphasized that service speed mattered during arrival, seating, ordering, serving food and drinks and during payment while at the front desk, service delivery speed was important during check-in, check-out, porterage, use of telephone, message delivery and when providing room service.

Further, several key cross-functional business processes will depend on how management has structured processes. According to Jones (2008) some organizations have identified as few as five, while others (e.g. IBM) have identified 23. The computer and developments in telecommunication are most important aspects of information technology that have transformed business environment and processes (Gunasekaran, 2008). From an operational perspective, system manages all facets of the booking process. Through the system, the hotel can create offer packages, confirm rooms, conduct payments, and process payments. According to set of filters, the system can automatically understand popular seasons as well as high occupancy and can further assist in keeping a hotel near full occupancy while avoiding over occupancy resulting in monetary losses in compensation for over-booking. Again, specific rules and commands can be made internally. An example is that if availability is higher than 35 percent, and the booking was reserved more than 30 days prior to the preferred dates in high season, then increase the room price by 20 percent. If availability is lower than 35 percent, and the booking was reserved more than 30 days prior to the preferred dates during shoulder season, then increase the room price by 25 percent. The hotel has complete control over automated commands. The process helps the organization to save money that may have been lost in the past and maintain a consistent booking schedule (McGregor, 2018). An effective strategy involves matching a hotel's products and services with its resource capability. There is little point in trying to gain a competitive advantage if the resources required are not available or cannot be made available. The above literature demonstrates clearly how these internal processes impart on the organization's competitiveness.

\section{Methodology}

A survey was used to sample out 92 respondents from a target population of 120 managers of Kigali Serena who were Hotel officials accountable for execution contracting and heads of divisions to be specific; ICT, Human Resource 
Management, Finance, and Customer administration. An open-ended questionnaire was used to collect primary data whereas the review of literature adopted a secondary data collection method. This study embraced a graphic research structure. Quantitative research gathers information as numbers and uses factual kinds of information investigation (Blanche et al., 2016).

The data collected was analyzed using the Statistical Package for social sciences (SPSS). Kothari (2014) describes masses as a far-reaching game plan of the examination of all people from certifiable or theoretical game plan of people events or articles to which the authority used to summarize the result.

The testing method characterizes the principles that determine how the framework ascertains the example size and it contains data about the valuation of an examination trademark during results recording. Straightforward irregular inspecting method was utilized in choosing tests. This likelihood examining system is additionally alluded to as agent inspecting (Deming, 2016). It was favored for this investigation since it gave equivalent opportunities to all people inside the populace to be tested. It likewise guarantees genuine portrayal study. The specialist begins by making a total rundown of the populace from which to choose the examples. Each name of the worker was then allocated a number after which the numbers were put in a compartment and blended altogether. The scientist at that point picked the numbers individually without reimbursement until 92 examples are gotten.

An aggregate of 92 representatives comprised the example size for this investigation. The example size was measurably determined utilizing Slovin's equation $(n)=N / 1+N(e)^{2}$

Where;

$\mathbf{n}$ is the sample size,

$\mathbf{N}$ is the population size (120)

e is the desired level of precision (0.05)

$n=\frac{120}{1+120(0.05) \wedge 2}=92$

\begin{tabular}{|c|c|c|}
\hline Area of Operation & Population & Proportions \\
\hline Managers & 10 & 8 \\
\hline Supervisors & 20 & 15 \\
\hline Cooks & 48 & 37 \\
\hline Room attendants & 10 & 8 \\
\hline Waiter & 14 & 10 \\
\hline Front desk & 18 & 14 \\
\hline Total & 120 & 92 \\
\hline
\end{tabular}

Table 1: Sampling Frame

A self-structured survey on worker commitment was utilized as an information accumulation device. It was utilized to gather data with respect to the apparent impact of workers' commitment techniques on execution of the lodging. It was dispersed to the examination individuals by the researcher herself and the respondents was drawn closer to express how much they agree or can't resist negating the declaration using a 5-point Likert scale. Meeting aide was utilized to gather information from directors and managers.

Authenticity chooses if the investigation truly measures what it was relied upon to evaluate or how legit the assessment results are. The investigation applied a build legitimacy test by Dividing number of legitimate cases and all out number of cases and increasing by 100 . This was finished by submitting draft survey to the chiefs for audit and suggestions.

Cronbach's alpha enduring quality coefficient was utilized to test for unwavering quality. This coefficient expands some place in the scope of 0 and 1 and the coefficient progressively significant faithful nature of the assessment instrument (Taherdoost, 2016).

Prior to preparing the reactions, the finished surveys fulfillment altering done to decide off base, fragmented, or nonsensical information and after that improve the quality through revision of recognized blunders. Enlightening measurements was directed through expressive investigation to create frequencies, rates, means and sexually transmitted disease. Deviation. Inferential insights explicitly relapse examination was utilized to decide the connection between the factors. Subjective information gathered through meetings was sorted out into topics and after that dissected fittingly. Topical investigation includes looking into information, make notes and afterward sort it into classes. SPSS was utilized for the information examination. Study discoveries were exhibited utilizing tables.

$\mathrm{Y}=\alpha+\beta_{1} \mathrm{X}_{1}+\beta_{2} \mathrm{X}_{2}+\beta_{3} \mathrm{X}_{3}+\beta_{4} \mathrm{X}_{4}+\mu$

$\mathrm{Y}=$ Dependent variable - Organizational Competitiveness

$\alpha=$ Constant

$\mu=$ Error

$\beta=$ Coefficient

$\mathrm{X} 1$ = Financial perspective

$\mathrm{X}_{2}=$ Internal business perspective

X3 = Learning and growth perspective 
To test the connection between the factors (decision of credit offices and budgetary execution), the examination received both expressive and inferential investigation. The inferential measurable techniques to be utilized in this investigation are connection coefficient $(r)$ and Pearson relationship coefficient. The trial of hugeness to be utilized are relapse examination expected to yield the coefficient of assurance (R2), investigation of fluctuation alongside the significant $\mathrm{t}$ - tests, $\mathrm{f}$ - tests, $\mathrm{z}$ - tests and $\mathrm{p}$ - values. The decisions of these methods are guided by the factors, test size and the exploration structure. The inferential measurable procedures were done at 95\% certainty level $(\mathrm{a}=0.05)$. The information was examined utilizing the Software (SPSS) variant 21.0. Quantitative was utilized to present outcomes in type of charts and tables.

\section{Results and Findings}

The study made use of both primary and secondary data. The model size for this assessment was 92 respondents who were the departmental bosses in Serena hotel in Kigali. Out of the 92 overviews offered out to the examined respondents, 72 examinations were done and returned. This response rate of $76.1 \%$ was viewed as high enough for appraisal. As shown by Baruch and Holtom (2008), 52.7\% is the average level of response rate from a survey of several social science studies satisfactory for evaluation and hypothesis of the outcomes.

\begin{tabular}{|c|c|c|}
\hline Response & Frequency & Percentage \\
\hline Questionnaire returned & 72 & 78.2 \\
\hline Questionnaire unreturned & 20 & 21.8 \\
\hline Total & 92 & 100.0 \\
\hline
\end{tabular}

Table 2: Rate of Response from Questionnaires

Respondents in the study were queried about various internal business indicators of their organization. That is capacity utilization, response time and Process capability. The internal effects of quality on competitiveness were estimated using average direct costs. The sign and value of the estimated coefficients were used to examine a set of hypotheses for improving the competitiveness of hotels. The direct, positive effect of high service quality on competitiveness is a particularly important finding. Majority (84.6\%) of the respondents indicated that their organization strives to improve quality boost internal business processes. While a lower proportion expressed confidence in the organization's tendering process, overall, the respondents rated the organization's internal business perspective very highly as shown in Figure below.

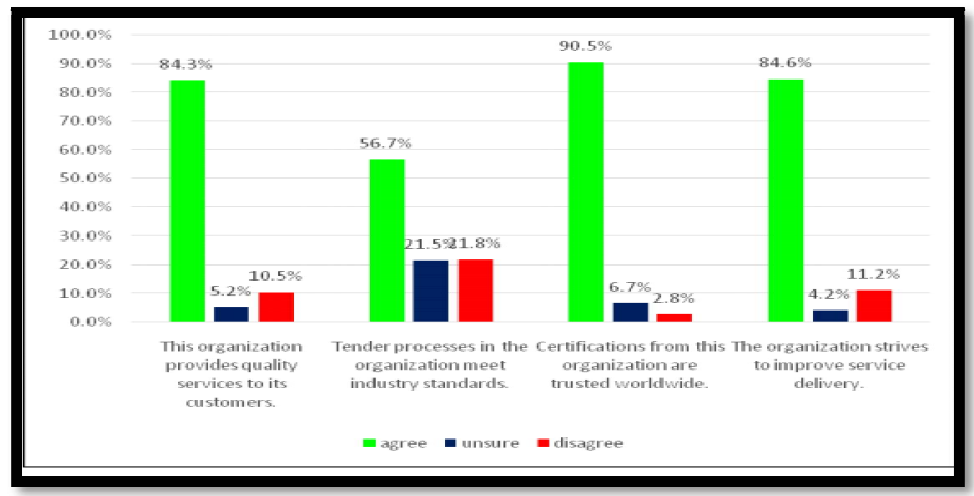

Figure 1: Respondents View on Internal Business Perspectives

\begin{tabular}{|c|c|c|c|c|c|c|c|}
\hline $\begin{array}{r}\text { Variables } \\
\end{array}$ & 1 & 2 & 3 & 4 & 5 & 6 & 7 \\
\hline $\begin{array}{c}\text { The Balanced Scorecard furnishes the } \\
\text { board with a far-reaching picture of } \\
\text { business activities }\end{array}$ & 1 & & & & & & \\
\hline $\begin{array}{c}\text { Exercise measures of how well the } \\
\text { company identifies the customers' } \\
\text { future needs }\end{array}$ & .752 & 1 & & & & & \\
\hline $\begin{array}{l}\text { Creativity and Unexpected Ideas } \\
\text { Increased }\end{array}$ & .365 & -0.019 & 1 & & & & \\
\hline Exercise quality measures & 0.489 & $0.406^{*}$ & $.496 *$ & 1 & & & \\
\hline Exercise of response time measures & 0.081 & 0.421 & 0.236 & 0.32 & 1 & & \\
\hline Existence of costs measures & $570^{*}$ & $.470 *$ & 0.125 & $.604^{* *}$ & 0.489 & 1 & \\
\hline $\begin{array}{c}\text { Existence of Post sales service measures } \\
\text { - measures for warranty, repair and } \\
\text { treatment of defects and returns }\end{array}$ & 0.081 & 0.421 & 0.236 & 0.32 & $.604^{* *}$ & 0.489 & 1 \\
\hline
\end{tabular}

Table 3: Correlation Matrix for Internal Business Perspective and Organization Competitiveness

Internal Business Perspective: 1 = Strongly Disagree, 2 = Disagree, 3 = Unsure, $4=$ Agree, 5 = Strongly Agree 


\subsection{Multivariate Analysis}

To adjust for confounding, all the Internal Business Perspective variables that significantly correlated with Performance were modelled together using Multiple Linear Regression. The results of the regression for Performance indicated that the predictors (Internal Business Perspective variables) explained $23.6 \%$ of the variance in Organizational Performance ( $2=0.35, F=3.18, p=0.03$ ). Provision of good quality services $(\beta=0.36, p=0.02)$ significantly predicted higher employee perception of organizational competitiveness.

\section{Discussions}

A common view among academic researchers is that the key to superior performance is to gain a competitive advantage (Vargo and Lusch, 2004). During the last decade one of the main themes to dominate the strategy literature has been the resource-based view of the firm (Barney, Wright and Ketchen 2001; Newbert, 2006) which suggests two ways to obtain competitive advantage. Advocates of the resource-based view are of the opinion that strategy must be embedded in the firm's resources (inputs) and capabilities (processes). The study speculates that exemplar hotels obtain competitive advantage by making more effective use of inputs and processes vis-a-vis its peer groups. According to Barney and Clark (2007) the importance of resources and capabilities rests on two premises. First, internal resources and capabilities provide the basic direction for a firm's strategy. Second, resources and capabilities are the primary source of profit for the firm. Therefore, a major implication for the study is the need to identify the processes that can lead to competitive advantage. However, this is often problematic for several reasons. First, as capabilities are deeply embedded within the fabric of the organization, they are often hard to identify (Vargo and Lusch, 2004). Second, a capability is developed when employees repeatedly apply their intangible knowledge and skills to transforming inputs to outputs. To accomplish this change, there is frequently an interaction between intangible and tangible resources or assets. Third, environmental characteristics can impact on the hotel's capabilities. This may help develop the knowledge and skills that evolve into capabilities (Osterloh and Frey, 2000).

\section{Conclusions and Recommendations}

Professionally qualified managers displayed improved execution as far as improved visitor profile quality, inflow of new thoughts from their staff to speed up response time and decrease in issues identified with supervision were concerned. More seasoned administrators additionally demonstrated to yield better outcomes in the inspected lodgings.

Consumer loyalty files, polls and visitor input reports in the five-star hotel in Rwanda means that administration is additionally discovering methods for visitor involvement. Hotels today are some of the most complex organizations with dozens of moving parts that must work seamlessly together to maintain efficiency and customer satisfaction. Internal Business Processes provide a practical framework for consistent service quality and improvement among guests. Consistent rules, procedures, policies, and branding across all hotels make the customer experience one that is most memorable, creating a brand that customers can trust. One the most regular complaints among regular lodgers on any travel forum is the inconsistency with which hotels and other travel companies apply their rules and procedures, often turning neutral customers into angry customers. Internal processes for physical operations remain cardinal entities that also ensure all work together for competitive advantage.

It can be assumed that hotels would retain a much larger percentage of clientele if it had stronger processes and procedures in place to unify employee functions and better serve the customer. For example, often, when a customer registers their information for an online booking with a third- party website, the customer arrives and must fill out more information for the hotel system. A good process capability system can help to further simplify the check-in of the guest by automating the documentation so that only a signature may be required upon arrival. The same process can be applied to that of housekeeping service. Housekeeping can utilize a process capability system to view which rooms need to be serviced, which rooms are occupied, which guests have requested a late check-out, and even which rooms are completed for future guest arrival. This makes for a simplified and organized model, allowing for no confusion between floors or shifts.

In a nutshell, the transformation of the internal business processes creates a sustainable competitive advantage for the hotel accommodation business in Rwanda where customers are retained through positive experiences with all departments in the hotel. Check in and buying processes are made simple, activities made more accessible, housekeeping made more reliable, and experiences made more enjoyable, creating customer retention and established trust.

\section{References}

i. Barney, J. B., and Clark, D. N. (2007). Resource-Based Theory: Creating and Sustaining Competitive Advantage. Oxford University Press, Oxford, UK.

ii. Barney, J., Wright, M., and Ketchen, D. J. (2001). The resource-based view of the firm: Ten years after 1991, Journal of Management, 27(2001), pp. 625-641.

iii. Baruch, Y. and Holtom, B. C. (2008). Survey response rate levels and trends in organizational research. Human relations, 61, 8, pp. 1139-1160.

iv. Burton, R. M., Obel, B. and Håkonsson, D. D. (2015). Organizational Design: A Step-by-Step Approach (3rd Edition). Cambridge University Press, United Kingdom.

v. Bourne, M., Neely, N., Platts, K. and Mills, J. (2010), The success and failure of performance measurement initiatives: perceptions from participating managers, International Journal of Operations \& Production Management, Vol. 22 No. 11, pp.1288-310. 
vi. Crandall, R. E., and Markland, R.E. (1996). Demand Management - Today's challenge for service industries. Production and Operations Management. Vol 5(2), pp. 106-120

vii. Deming, E. W. (2016). Out of the Crisis, Quality, Productivity and Competitive Position, Cambridge, United Kingdom.

viii. Efendioğlu, D. and Bulkan, S. (2017). Capacity Management in Hotel Industry for Turkey, In book: Handbook of Research on Holistic Optimization Techniques in the Hospitality, Tourism, and Travel Industry, DOI: 10.4018/978-1-5225-1054-3.ch013.

ix. Fitzsimmons, J.A. and Fitzsimmons, M.J., 2006. Service management: operations, strategy, information technology. Irwin, NY: McGraw-Hill

x. Gunasekaran, A. (2008). Global Implications of Modern Enterprise Information Systems: Technologies and Applications. Information Science Reference, New York, USA.

xi. Jones Peters (2008). Handbook of Hospitality Operations and IT, Ed. Peters Jones, Routledge.

xii. Klassen, K.J. and Rohleder, T.R., (2002). Demand and capacity management decisions in services; how they impact on one another. International Journal of Operations and Production Management, 22 (5), 527-548

xiii. Kothari, C. R. (2014). Research Methodology: Methods and Techniques(paperback). New Age International Publisher, Delhi, India.

xiv. McGraw-Hill Ansoff, H. I. and McDonnell, E. J. (1990). Implementing Strategic Management

xv. (12th Ed.) Englewood Cliffs, NJ: Prentice Hall, Europe

xvi. McGregor M. (2018), How hotels can retain customers through Process Management. [Online] Available at: https://www.fsrmagazine.com/hotel-lodging/how-hotels-can-retain-customers-through-processmanagement. Accessed on 13 September 2019.

xvii. Newbert, S. L. (2007). Empirical research on the resource-based view of the firm: an assessment and suggestions for future research, Strategic Management Journal, Vol. 28, Issue 2, pp. 121-146. DOI: 10.1002/smj.57.

xviii. Osterloh, M. and Frey, S. (2000). Motivation, Knowledge Transfer, and Organizational Forms. Organization Science. Vol. 11, Issue 5. pp. 473-585.

xix. Pullman, M. and Rodgers, S. (2010), Capacity management for hospitality and tourism: A review of current approaches, International Journal of Hospitality Management, Vol 29 (1), pp 177-187.

xx. Taherdoost, T. (2016). Validity and Reliability of the Research Instrument; How to Test the Validation of a Questionnaire/Survey in a Research. SSRN Electronic Journal, 5(3), pp. 28-36

xxi. Ta-Wei Tang \& Michael Wang \& Ya-Yun Tang, 2015. "Developing service innovation capability in the hotel industry," Service Business, Springer; Pan-Pacific Business Association, vol. 9(1), pages 97-113, March.

xxii. Teece, D. J., (2009). Dynamic Capabilities and Strategic Management: Organizing for Innovation and Growth, Oxford University Press, Oxford, UK.

xxiii. Saarinen, J., Rogerson, C, M. \& Hall, C. M. (2017). Geographies of tourism development and planning, Tourism Geographies, 19:3, 307-317, DOI:10.1080/14616688.2017.1307442

xxiv. Vargo, S. L. and Lusch, R. F. (2004), Evolving to a New Dominant Logic for Marketing. Journal of Marketing, Vol. 68 No. 1 (Jan. 2004). Pp. 1-17. 